\title{
The role of cigarettes and nicotine in the onset and treatment of ulcerative colitis
}

\begin{abstract}
Summary
Epidemiological evidence suggests that ulcerative colitis is a disease of nonsmokers, while Crohn's disease is a disease of smokers. The relative risk of developing ulcerative colitis is not only greater in nonsmokers, in addition there appears to be a rebound effect in smokers who quit, with the heaviest (ex-)smokers increasing their relative risk of the disease the most. This factor poses an ethical dilemma for health professionals giving advice on stopping smoking, which may thus have a serious detrimental effect on the health of some patients. Nicotine is believed to be the pharmacological ingredient of tobacco that is responsible for this beneficial effect and several clinical trials using nicotine have demonstrated it to be an effective therapeutic agent in the treatment of ulcerative colitis. Although the aetiology of ulcerative colitis is unclear, current research using nicotinebased products has produced some interesting clues, together with the possibility of some form of therapeutic treatment based on nicotine administration.
\end{abstract}

Keywords: ulcerative colitis, cigarette smoking, nicotine

\begin{tabular}{|l|}
\hline Ulcerative colitis \\
\hline - ulcerative colitis is a recurrent \\
inflammatory and ulcerative disease \\
of the colon and rectum \\
onset is characterised by the \\
development of lesions in the \\
mucosal layer from the rectum \\
extending proximally into the colon \\
- symptoms include rectal bleeding, \\
diarrhoea, cramping and abdominal \\
pain, anorexia and weight loss \\
incidence: $5-10$ per 100000 \\
- prevalence: 100 per 100000 \\
\hline
\end{tabular}

Box 1

Department of Psychiatry, University of Southampton, Faculty of Medicine, Royal South Hants Hospital, Southampton SO14 OYG, UK J Birtwistle

Accepted 24 January 1996

\section{Jon Birtwistle}

Cigarette smoking has long been associated with diseases of the lungs ${ }^{1-3}$ and cardiovascular system, ${ }^{4-7}$ and evidence suggests that stopping smoking is the most important factor in reducing both mortality, ${ }^{8,9}$ and morbidity ${ }^{10}$ from coronary heart disease. There is, however, evidence to suggest that smoking may also confer some protection against ulcerative colitis. ${ }^{11}$

In this article, the evidence that nicotine is both protective against the development of ulcerative colitis and a useful clinical treatment of its symptoms is reviewed. Four main areas are examined. Firstly, there is a brief overview of the pathophysiological mechanisms involved in the development of ulcerative colitis; secondly, the evidence of a link between tobacco and ulcerative colitis is outlined; thirdly, the use of nicotine as a clinical treatment is evaluated and, finally, the possible actions of nicotine and smoking are discussed.

\section{Ulcerative colitis}

Ulcerative colitis has been defined as "a recurrent inflammatory and ulcerative disease of the colon and rectum, characterised clinically by rectal bleeding, diarrhoea, cramping and abdominal pain, anorexia, and weight loss". ${ }^{12}$ Ulcerative colitis is one of the two major nonspecific inflammatory bowel diseases, the other being Crohn's disease. Its onset is characterised by lesions that develop in the base of the mucosal layer, originating in the rectum and extending proximally into the colon, which eventually ulcerate due to immunological inflammatory processes, producing the abovementioned symptoms. The aetiology of ulcerative colitis is unknown and probably reflects a heterogeneous disorder. Shanahan suggests "an interaction between genetic predisposing factors, exogenous and endogenous triggers, and modulating factors". ${ }^{13}$ One suggested exogenous trigger is that of some harmful substance that penetrates the bowel wall, initiating the inflammatory response. ${ }^{14}$

Epidemiological data suggests that the incidence of ulcerative colitis is $5-10$ per 100000 and the prevalence about 100 per $100000,{ }^{15}$ with the peak age at presentation being in the third decade. ${ }^{16}$ Ulcerative colitis appears to be more common in whites than blacks and, in the white population, more common in Jews and northern Europeans. ${ }^{12}$

Cope and Heatley suggest three main factors that may have an important role in the development of ulcerative colitis: mucosal epithelial defences, mucosal immune defences and inflammatory mediators. An examination of the mucosal epithelium indicates that patients with ulcerative colitis have a thin mucus layer, ${ }^{17}$ thereby making them more predisposed to intestinal mucosal assault. The response of the colon in patients with ulcerative colitis is that of chronic inflammation, suggesting that there may be an abnormal immune response in these patients. Shanahan suggests that non-autoimmune mucosal T-cell activation also plays a major role in the clinical symptoms of ulcerative colitis. Persistent or unchecked mucosal $\mathrm{T}$ cell activation increases the production of cytokines which mediate the inflammatory process. Direct cytokine effects on the mucosal tissue include the stimulation of the growth of intestinal crypt cells. At present, the stimulus for T-cell activation remains a puzzle, although Shanahan proposes that an interaction between genetic factors and colonic microbial flora may play a part. ${ }^{13}$

Chronic inflammation is known to be perpetuated by numerous inflammatory mediators, particularly the eicosanoids, which include the prostaglandins. Prostaglandin E2 (PGE2) levels are raised in ulcerative colitis. ${ }^{17}$ There is, however, some evidence to support the role of PGE2 in the protection of the mucosa from colitis in rats, ${ }^{18}$ although it is difficult to reconcile this view with the evidence supporting an inflammatory role of PGE2 in the development of ulcerative colitis. There are also several immunological changes that are characteristic of ulcerative colitis, namely an increase in plasma cells and 


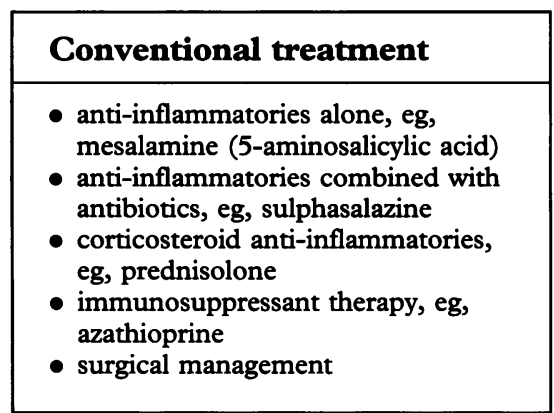

Box 2

\begin{tabular}{|l|}
\hline Smoking and ulcerative \\
colitis \\
\hline - ulcerative colitis is a disease of \\
nonsmokers and ex-smokers \\
- Crohn's disease is a disease of \\
smokers \\
- there is no evidence of a disease \\
prodrome predisposing patients to \\
quit smoking \\
- there is a rebound effect in smokers \\
who quit; $52 \%$ develop symptoms \\
within three years of quitting \\
- heavy smokers who quit have an \\
increased relative risk of 4.4 \\
anecdotal evidence suggests that \\
ex-smokers who recommence \\
smoking experience a relief of \\
symptoms
\end{tabular}

Box 3 specific increases in immunoglobulins (Ig) IgG and IgM, with IgA levels remaining mostly unchanged. ${ }^{17}$

Another major effect on the inflammatory response is the local influx of neutrophils which are believed to mediate most change in ulcerative colitis. Neutrophils are known to release chemotaxic factors such as leukotriene B4 (LTB4) which attracts more neutrophils and other acute inflammatory cells, thereby escalating the inflammatory response. ${ }^{13}$ The treatment of ulcerative colitis has mainly concentrated upon treatment of the inflammatory response by the administration of anti-inflammatories alone (eg, mesalamine), antibiotics in combination with anti-inflammatories (eg, sulphasalazine), the administration of corticosteroid anti-inflammatories (eg, prednisolone), or immunosuppressant therapy (eg, azathioprine). ${ }^{19,20}$ Surgical management is required when acute emergency complications such as toxic megacolon occur or there is a failure to control the symptoms. In its acute stage, ulcerative colitis can be a lifethreatening disease.

\section{Tobacco and ulcerative colitis}

Ulcerative colitis has been described as a disease of nonsmokers, ${ }^{1,21-27}$ while Crohn's disease is a disease of smokers. ${ }^{27-29} \mathrm{~A}$ comprehensive meta-analysis carried out by Calkins demonstrated a relationship between smoking and both these diseases. In ulcerative colitis, nonsmoking was seen as a causal factor, while the converse was true for Crohn's disease. ${ }^{30,31}$

A questionnaire carried out by Harries et al indicated that only $8 \%$ of patients with ulcerative colitis were smokers while $42 \%$ of those with Crohn's disease were smokers. The non-smoking behaviour was not explained by a cessation of smoking due to the symptoms of the disease as $48 \%$ of ulcerative colitis and $30 \%$ of Crohn's disease patients had never smoked. Forty per cent of ulcerative colitis patients were ex-smokers who had stopped, on average, 13 years previously. ${ }^{11}$ A similar difference in smoking habits was found by Bures et al. ${ }^{32}$ The relative risk of developing ulcerative colitis is not only greater in nonsmokers, there also appears to be a rebound effect in smokers who quit. ${ }^{33}$ Motley et al ${ }^{34}$ found that $52 \%$ of ulcerative colitis patients developed the disease within three years of stopping smoking; they also suggest that smoking may delay the appearance of ulcerative colitis in males. Heavy smokers who quit increase their relative risk of ulcerative colitis by 4.4. ${ }^{35}$ Boyko et al found no evidence to suggest a disease prodrome, that caused patients to stop smoking. Subjects who stopped smoking four years or more before the onset of ulcerative colitis had the greatest risk. ${ }^{36}$ This link between quitting smoking and the development of ulcerative colitis has proved to be a puzzle. Its solution may give some insight into the aetiological factors associated with ulcerative colitis and Crohn's disease. Quitting smoking is often associated with other changes in health behaviour aimed at promoting health, such as an increase in exercise and a reduction in alcohol intake. Quitting smoking may also lead to weight gain and attempts to lose this through changes in diet and increased exercise. ${ }^{36}$ Interestingly, Boyko et al demonstrated a negative association between alcohol intake and the risk of ulcerative colitis, with beer drinkers having the lowest risk for this disease. ${ }^{37}$ Such evidence creates an interesting dilemma for physicians who have to advise patients with colitis who are either current smokers or ex-smokers. To advise current smokers to quit may put the sufferer at serious risk of developing ulcerative colitis which would be detrimental to their health, may increase the risk of surgery and could prove fatal if they suffer an acute episode. If a physician were to advise an exsmoker with colitis to commence smoking then they could be deemed negligent should that patient develop a disease associated with smoking. Unfortunately, the evidence appears to indicate that smoking and drinking may be the best way to avoid ulcerative colitis!

De Castella describes a patient who developed ulcerative colitis within weeks of stopping smoking. After nine months unsuccessful treatment she became so demoralised that she started smoking again. Within two weeks there was a dramatic improvement and after a further four weeks the symptoms had disappeared. The patient attempted to stop smoking on several subsequent occasions which resulted in the onset of the symptoms which again subsided when smoking was recommenced. ${ }^{22}$ A similar case was described by Roberts and Diggle who hypothesised that nicotine was the pharmacologically active ingredient in the cigarette responsible for the remission of symptoms. To test this hypothesis they substituted nicotine gum for the cigarettes and after various dose levels found that remission of the symptoms could be maintained at nicotine doses of $4 \mathrm{mg}$ five times a day. A lower dose regime of $4 \mathrm{mg}$ twice daily 


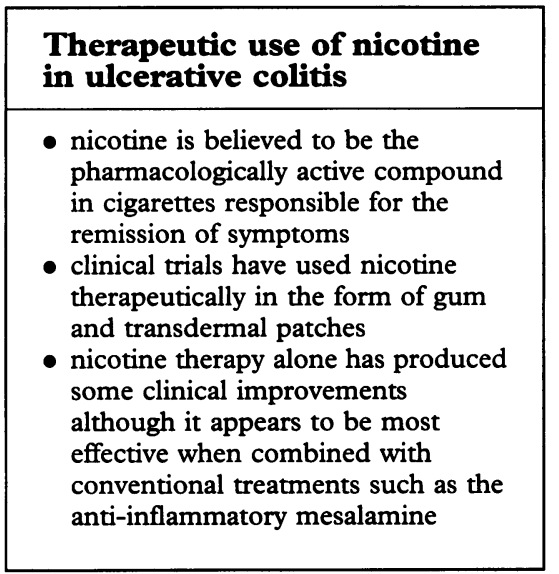

Box 4

\begin{tabular}{|l|}
\hline Side-effects of nicotine \\
\hline - nausea \\
- light headedness \\
- headache \\
- sleep disturbance \\
\hline
\end{tabular}

Box 5

\begin{tabular}{|l|}
\hline Nicotine: possible \\
pharmacological effects \\
\hline - induces changes in the rectal mucosa \\
- influences immunological and \\
inflammatory mediators \\
- reduces rectal blood flow \\
- decreases intestinal permeability \\
- replaces or enhances a biochemical \\
deficit \\
\hline
\end{tabular}

Box 6 plus $2 \mathrm{mg}$ twice daily resulted in an 'explosive relapse'. ${ }^{38}$ Interestingly, Jick and Walker also noted that the ratio of the prevalence of ulcerative colitis compared to controls was lower in heavy smokers (two packs or more a day) than light smokers (less than half a pack a day). For men this figure was 0.13 and 0.35, respectively. ${ }^{25}$ It has been estimated that nicotine intake in smokers can vary between 0.4 to $1.6 \mathrm{mg}$ per cigarette, therefore an estimation of the daily intake of nicotine for light (10 cigarettes) and heavy (20 cigarettes) smokers would be $4-16 \mathrm{mg}$ and $8-32 \mathrm{mg}$, respectively. ${ }^{39}$

\section{The clinical use of nicotine}

Lashner et al examined the use of nicotine gum as a treatment for ulcerative colitis in a series of single-patient double-blind cross-over trials. During the nicotine period, patients chewed up to 10 squares of gum a day $(20 \mathrm{mg})$ for a period of two weeks. Three of seven patients demonstrated an improvement in self-reported symptoms and two of these had clinical improvements in proctoscopic examination. None of these patients suffered side-effects. Of the remaining four patients, one was withdrawn due to side-effects and the other three failed to make significant improvement. ${ }^{40}$

The use of transdermal nicotine patches combined with 'conventional' treatments has also proved promising. Pullan et al compared transdermal nicotine and placebo patches in ulcerative colitis patients receiving the antiinflammatory mesalamine (5-aminosalicylic acid). The results demonstrated that 17 out of 35 patients in the nicotine group compared to nine out of 37 in the placebo group had a complete remission $(p<0.05)$. The nicotine group also demonstrated greater improvements in several clinical measurements, including the histologic grade, abdominal pain and faecal urgency. There were, however, more side-effects reported in the nicotine group, including nausea, light headedness, headache, and sleep disturbances. ${ }^{26}$ Transdermal nicotine treatment alone has not been as effective. Thomas et al assessed the use of transdermal nicotine without mesalamine and concluded that nicotine alone was no more effective than placebo at maintaining remission. ${ }^{41}$ Hanauer is, however, critical of such studies, due to the lack of an accepted standard of therapeutic improvement and therefore objective measurement. ${ }^{19}$ Most studies rely on subjective measurements of the way patients feel they have improved, which can be unreliable.

In any clinical evaluation of nicotine one must acknowledge that nicotine is a highly addictive substance, ${ }^{42}$ and this factor demands that a careful clinical evaluation is made, taking this and other potential side-effects into consideration. It should, however, be pointed out that nicotine has no role in tobaccorelated cancers and Russell argues that no carcinogenic metabolite has been demonstrated. ${ }^{43}$ Recent evidence from Thomas et al has even suggested that transdermal nicotine may beneficially influence cardiovascular risk factors by reducing plasma fibrinogen levels. ${ }^{44}$

\section{The possible protective and therapeutic effects of nicotine}

There have been several proposed hypotheses to account for the association between smoking and the reduced risk of developing ulcerative colitis; most have looked at the pharmacological effects of nicotine. However, the actual act of smoking must not be overlooked, as this in itself has an influence upon many immunological factors, in addition to the nicotine effect. Research has indicated several possible areas that may be influenced by smoking and nicotine. Five will be outlined below.

\section{MUCUS PRODUCTION IN THE RECTAL MUCOSA}

Nonsmokers with ulcerative colitis demonstrate significantly lower mucus production in the rectal mucosa than nonsmoking controls. However, ulcerative colitis patients who smoke are comparable to control patients who smoke. ${ }^{23,45}$ It is interesting to note that mucus production is not influenced by the addition of tobacco products in vitro ${ }^{23}$ and evidence from Ryder et al suggests that smoking has no effect upon mucus synthesis. ${ }^{46}$

Zijlstra et al examined the effects of nicotine on the rectal mucus and mucosal eicosanoids of rabbits. The thickness of adherent mucus on the rectal mucosa was found to be significantly reduced by low doses and increased by high doses of nicotine. All eicosanoid levels were reduced by nicotine, some demonstrating an inverse dose-dependent curve with the greatest reduction at the lowest doses. They suggest that nicotine may influence ulcerative colitis through its action on mucosal eicosanoids and adherent surface mucus secretion. ${ }^{47}$ 
IMMUNOLOGICAL AND INFLAMMATORY MEDIATORS

In addition to nicotine, the act of smoking may be an important factor. Heavy smoking is known to depress natural killer cell activity. ${ }^{48}$ Acute exposure to cigarette smoke has been shown to impair neutrophil adherence and movement. ${ }^{49}$ There is also a significant reduction in the concentration of IgA within the intestinal fluid ${ }^{50}$ and an increase in IgE serum levels. ${ }^{51}$ In saliva there is a significant reduction in IgA and an increase in IgM. ${ }^{52}$ Although there is an obvious link between smoking and immunological factors, Srivastava et al argue that there is insufficient evidence to associate the beneficial effect of smoking on ulcerative colitis with these immunological changes. ${ }^{50}$ An interesting finding was that heavy smoking (more than 20 cigarettes a day) had the effect of reducing PGE2 levels in gastric mucosa; in vitro colonic production of eicosanoids in healthy control smokers was also reduced. However, light smokers (less than 10 cigarettes daily) showed an increased in vitro production of PGE2. ${ }^{17}$ Rudra et al found that ex-smokers with ulcerative colitis who recommenced smoking had to smoke an average of 20 cigarettes a day to have a beneficial effect. ${ }^{53}$ The findings by Zijlstra et al may indicate that nicotine is the main factor in this effect, as low doses may reduce rectal mucosa while high doses increase it. ${ }^{47}$

Several theories have postulated that psychological factors such as stress play a part in the aetiology of ulcerative colitis, through effects upon the immune system. Anecdotal evidence does suggest that smoking may reduce stress levels and have a positive effect on the symptoms of ulcerative colitis. However, research evidence contradicts this viewpoint for two reasons. Firstly, research in health psychology has produced little evidence to suggest that stress triggers or exacerbates the symptoms of ulcerative colitis. ${ }^{54}$ Secondly, even if stress were linked to the trigger of ulcerative colitis, it would not account for the fact that most patients develop the symptoms three years following the cessation of smoking. ${ }^{33}$

\section{REDUCING RECTAL BLOOD FLOW}

Srivastava et al found that rectal blood flow was significantly reduced in the first hour following a cigarette. ${ }^{55}$ This is thought to be due to the effects of nicotineinduced vasoconstriction associated with a transient rise in blood pressure. The reduced blood flow may cause a decrease in the amount of inflammatory mediators reaching the mucosal surface, thereby reducing the inflammatory response and symptoms, or somehow improve the protection of the mucosa, perhaps by increasing mucus production. The effects on rectal blood flow produced by smoking could account for the discrepancy noted between heavy and light smokers, ${ }^{17,25}$ as heavy smokers would have a longer total period of reduced blood flow than light smokers.

\section{INTESTINAL PERMEABILITY}

Intestinal permeability is increased in patients with ulcerative colitis ${ }^{56}$ and it has been suggested that an increased intestinal permeability to harmful substances may be one causative factor in the development of ulcerative colitis. ${ }^{14}$ Research by Prytz et al has demonstrated that healthy smokers had a reduced permeability to ${ }^{51}$ chromium-labelled ethylenediaminetetraacetic acid compared to healthy nonsmokers. The authors suggest that smoking may act to 'tighten the gut' and may confer its beneficial effect upon ulcerative colitis by reducing intestinal permeability to exogenous causative substances. This effect is believed to be due to actions on the paracellular junction in the intestinal epithelium. ${ }^{14}$

\section{PHYSIOLOGICAL HOMEOSTASIS}

An interesting hypothesis put forward by Bowers et al is that, in patients with ulcerative colitis, cigarette smoking is an example of behavioural regulation of physiological homeostasis, in that nicotine acts to replace or enhance a biochemical deficit. As these authors argue "For some, ulcerative colitis is a nicotine-deficiency affliction which smoking or nicotine alleviates". ${ }^{57}$ Similarly, Hickey argues that nicotine increases the release of cellularly stored biogenic monoamine neurotransmitter hormones such as adrenalin. ${ }^{58}$ Therefore, patients with ulcerative colitis may have a deficiency in some biochemical factor which nicotine acts to correct. Most research has overlooked this possibility, which Hickey argues is due to statistical malpractice. Statistical correlation is incapable of distinguishing cause from symptom and therefore researchers making this error will overlook the possible link between nicotine and other factors not under experimental examination. 


\section{Conclusion}

At present, the pathophysiology of ulcerative colitis is unclear and the reason for the beneficial effects of smoking and nicotine unknown. The fact that there is a potential protective and therapeutic effect of smoking and/or nicotine posses a dilemma for physicians advising patients with this illness. One alternative may be to assess the effects of the patient taking a non-tobacco nicotine product, which may be both protective and therapeutic without the risks associated with tobacco use. Although the reason for the beneficial effects of nicotine on ulcerative colitis remains a puzzle, its utilisation may be clinically beneficial to some patients.

1 Doll $R$, Hill $A B$. A study of the aetiology of carcinoma of the lung. BMF 1952; 2: 1271-86.

2 Doll $R$, Hill AB. Lung cancer and other causes of death in relation to smoking. $B M \Im$ 1956; 2: 1071-6.

3 Fletcher C, Peto R. The natural history of chronic airflow obstruction. $B M \mathcal{F}$ 1977; 1: 1645-8.

4 Cook DG, Shaper AG, Pocock SJ, Kussick SJ. Giving up smoking and the risk of heart attacks. Lancet 1986; ii: 1376-80.

5 Fuster V, Chesebro JH, Frye RL, Elveback LR. Platelet survival and the development of coronary artery disease in the young adult. Effects of cigarette smoking, strong family history and medical therapy. Circulation 1981; 63: 546-51.

6 Kaufman DW, Helmrich SP, Rosenberg L, Miettinen OS, Shapiro S. Nicotine and carbon monoxide content of cigarette smoke and the risk of myocardial infarction in young men. $N$ risk of myocardial infarction in

7 Marshall T. Smoking and coronary heart distion of coronary heart disease. London: HMSO, tion of

8 Daly LE, Mulcahy R, Graham IM, Hickey N. Long term effect on mortality of stopping smoking after unstable angina and myocardial infarction. $B M f$ 1983; 287: 324-6.

9 Salonen JT. Stopping smoking and long-term mortality after acute myocardial infarction. $\mathrm{Br}$ Heart f 1980; 43: 463-9.

10 Rosenberg L, Kaufman DW, Helmrich SP, Shapiro S. The risk of myocardial infarction after quitting smoking in men under 55 years of age. $N$ Engl $₹$ Med 1985; 313: 1511-4.

11 Harries AD, Baird A, Rhodes J. Non-smoking: a Harries $\mathrm{AD}$, Baird A, Rhodes J. Non-smoking: a 12 Kirsner JB, Shorter RG. Recent developments in 2 Kirsner JB, Shorter RG. Recent developments in "nonspecific" inflammatory bow

13 Shanahan F. Pathogenesis of ulcerative colitis. Lancet 1993; 342: 407-11.

14 Prytz H, Benoni C, Tagesson C. Does smoking tighten the gut? Scand $\mathcal{F}$ Gastroenterol 1989; 24: 1084-8.

15 Thomas GAO, Rhodes J. Relationship between smoking and ulcerative colitis. I Smoking-Related Dis 1994; 5 (suppl 1): 75-8.

16 Price $\mathrm{AB}$. Inflammatory bowel disease. In: J O'D McGee, PG Isaacson, NA Wright, eds. Oxford textbook of pathology, Vol 2a. Oxford: Oxford textbook of pathology, Vol 2a. Oxfo
Oxford University Press, 1992; pp 1234-41.

17 Cope GF, Heatley RV. Cigarette smoking and Cope GF, Heatley RV. Cigarette smoking

18 Psaila RV, Myers B, Jones IR, Rhodes J. Effect of prostaglandin PGE2 on alcohol induced ulceration in the rat colon. Digestion 1986; 35: 224-8.

19 Hanauer SB. Nicotine for colitis - the smoke has not yet cleared. N Engl f Med 1994; 330: 856-7.

20 Hanauer SB. Medical therapy of ulcerative colitis. Lancet 1993; 342: 412-7.
21 Benoni C, Nilsson A. Smoking habits in patients with inflammatory bowel disease. A case-contro study. Scand 7 Gastroenterol 1987; 22: 1130-6.

22 De Castella H. Non-smoking: a feature of ulcerative colitis. BMF 1982; 184: 1706 .

23 Cope GF, Heatley RV, Kelleher J. Does cigarette smoking protect against ulcerative colitis by ette smoking protect against ulcerative colitis by 27: A618-7.

24 Gyde SN, Prior P, Taylor K, Allan RN. Cigarette smoking, blood pressure, and ulcerative colitis. Gut 1983; 24: A998.

25 Jick H, Walker AM. Cigarette smoking and ulcerative colitis. N Engl F Med 1983; 308: 261-3

26 Pullan RD, Rhodes J, Ganesh S, et al. Transdermal nicotine for active ulcerative colitis. $N$ Engl f Med 1994; 330: 811-5.

27 Osborne MJ, Stansby GP. Cigarette smoking and its relationship to inflammatory bowe disease: a review. $\mathcal{F} R$ Soc Med 1992; 85: 214-6. 8 Logan RFA, Somerville KW, Edmond M, wangman MJS. Is cigarette smoking associath Crohn's disease? Gut 1983; 24: A980.

29 Rhodes J, Thomas GAO. Smoking: good or bad for inflammatory bowel disease? Gastroenterology 1994; 106: 807-10.

30 Calkins BM. A meta-analysis of the role of smoking in inflammatory bowel disease. Dig Dis Sci 1989; 34: 1841-54.

31 Linberg E, Jarnerot G, Huitfeldt B. Smoking in Crohn's disease: effect on localisation and clinical course. Gut 1992; 33: 779-82.

32 Bures J, Fixa B, Komarkova O, Fingerland A. Non-smoking: a feature of ulcerative colitis. (letter) BMf 1982; 285: 440.

33 Motley RJ, Rhodes J, Ford GA, et al. Time relationship between cessation of smoking and relationship between cessation of smoking and onset $125-7$.

34 Motley RJ, Rhodes J, Kay S, Morris T. Late presentation of ulcerative colitis in ex-smokers. Int $\mathcal{F}$ Colorectal Dis 1988; 3: 171-5.

35 Lindberg E, Tysk C, Andersson K, Jarnerot G. Smoking and inflammatory bowel disease. A case control study. Gut 1988; 29: 352-7.

36 Boyko EJ, Koepsell TD, Perera DR, et al. Risk of ulcerative colitis among former and curren cigarette smokers. N Engl f Med 1987; 316: 707-10.

37 Boyko EJ, Perera DR, Koepsell TD, et al. Coffee and alcohol use and the risk of ulcerative colitis. Am $\mathcal{F}$ Gastroenterol 1989; 84: 530-4.

38 Roberts CJ, Diggle R. Non smoking: a feature of ulcerative colitis. $B M F$ 1982; 285: 440 .

39 Benowitz NJ, Jacob P III. Daily intake of nicotine during cigarette smoking. Clin Pharmanicotine during cigarette smo

40 Lashner BA, Hanauer SB, Silverstone MD. Testing nicotine gum for ulcerative colitis patients. Experience with single-patient trials. Dig Dis Sci 1990; 35: 827-32.

41 Thomas GAO, Rhodes J, Mani V, et al. Transdermal nicotine as maintenance therap for ulcerative colitis. $N$ Engl $\mathcal{F}$ Med 1995; 332 988-92.
42 Warburton DM. Psychopharmacological aspect of nicotine. In: Wonnacott S, Russell MAH, Stolerman IP, eds. Nicotine pharmacology, molecular cellular and behaviour aspects. Oxford: Oxford University Press, 1990; pp 77-111.

43 Russell MAH. The future of nicotine replacement. Br $\mathcal{F}$ Addict 1991; 86: 653-8.

44 Thomas GAO, Davies SV, Rhodes J, Russell MAH, Feyerabend C, Sawe U. Is transdermal nicotine associated with cardiovascular risk. $\mathcal{F} R$ Coll Physicians Lond 1995; 29: 392-6.

45 Cope GF, Heatley RV, Kelleher J. Smoking and colonic mucus in ulcerative colitis. $B M F$ 1986; 293: 481 .

46 Ryder SD, Raouf AH, Parker N, et al. Abnormal mucosal glycoprotein synthesis in inflammatory bowel disease is not related to cigarette smoking. Digestion 1995; 56: 370-6.

47 Zijlstra FJ, Srivastava ED, Rhodes M, et al. Effect of nicotine on rectal mucus and mucosal eicosanoids. Gut 1994; 35: 247-51.

48 Phillips B, Marshall ME, Brown S, Thompson JS. Effect of smoking on human natural killer cell activity. Cancer 1985; 56: 2789-92.

49 Selby C, Drost E, Brown D, et al. Inhibition of neutrophil adherence and movement by acute cigarette smoke exposure. Exp Lung Res 1992; 18: 813-27.

50 Srivastava ED, Barton JR, O'Mahony S, et al. Smoking, humoral immunity, and ulcerative colitis. Gut 1991; 32: 1016-9.

51 Zetterstrom O, Osterman K, Machado L Johansson SGO. Another smoking hazard: raised serum IgE concentration and increased risk of occupational allergy. $B M \mathcal{F} 1981 ; 283$ : 1215-7.

52 Barton JR, Riad MA, Gaze MN, Maran AGD, Ferguson A. Mucosal immunodeficiency in smokers, and in patients with epithelial head smokers, and in patients with epithelia

53 Rudra T, Motley R.J, Rhodes J. Does smoking improve colitis? Scand $f$ Gastroenterol 1989; 170 (suppl): 61-3.

54 Bennet P. Disorders of the gut. In: Broom A Llewelyn S, eds, Health psychology. Processes and applications, 2nd edn. London: Chapman and Hall, 1995; pp 225-43.

55 Srivastava ED, Russell MAH, Feyerabend C, Rhodes J. Effect of ulcerative colitis and smoking on rectal blood flow. Gut 1990; 31: 1021-4.

56 Jenkins RT, Jones DB, Goodacre RL, et al. Reversibility of increased intestinal permeability to $51 \mathrm{Cr}$-EDTA in patients with gastrointestinal inflammatory disease. Am $₹$ Gastroenterol 1987; 82: 1159-64.

57 Bowers EJ, Allen IE, Hickey RJ. Cigarette smoking: example of behavioural regulation of physiological homeostasis? Public Health Rep 1987; 99: 108-10.

58 Hickey RJ. Nicotine and ulcerative colitis. Gut 1989; 30: 416-8 